\title{
1 Sustainable Stabilization of Oil in Water Emulsions by Cellulose \\ 2 Nanocrystals Synthesized from Deep Eutectic Solvents
}

\author{
Ossi Laitinen ${ }^{\mathrm{a}, *}$, Jonna Ojala ${ }^{\mathrm{b}}$, Juho Antti Sirviö ${ }^{\mathrm{a}}$ and Henrikki Liimatainen ${ }^{\mathrm{d}}$ \\ a,* Corresponding author:
}

Ossi Laitinen, Postdoctoral Research Fellow, University of Oulu, Fibre and Particle Engineering, P.O. Box 4300, FI90014 Oulu, Finland, Phone: +358503504960, ossi.laitinen@oulu.fi

b Jonna Ojala, Researcher, University of Oulu, Fibre and Particle Engineering, P.O. Box 4300, FI-90014 Oulu, Finland, jonna.ojala@oulu.fi

c Juho Antti Sirviö, Postdoctoral Research Fellow, University of Oulu, Fibre and Particle Engineering, P.O. Box 4300, FI-90014 Oulu, Finland, juho.sirvio@oulu.fi

${ }^{\mathrm{d}}$ Henrikki Liimatainen, Associate Professor, University of Oulu, Fibre and Particle Engineering, P.O. Box 4300, FI90014 Oulu, Finland, henrikki.liimatainen@oulu.fi

\begin{abstract}
There is an urgent global need to develop novel types of environmentally safe dispersing chemicals from renewable resources in order to reduce the environmental impact of oil spills. For this goal, cellulose, the most abundant natural polymeric source, is a promising green, nontoxic alternative that could replace the current synthetic surfactants. In this study, cellulose nanocrystals (CNC) synthesized using a deep eutectic solvent (DES) and two commercially available cellulose nanocrystals were used as marine diesel oil-water Pickering emulsion stabilizers. In particular, oil in water $(\mathrm{o} / \mathrm{w})$ emulsion formation and stability of emulsified oil during storing were addressed using a laser diffraction particle size analyzer, image analysis, and oil emulsion volume examination. The particle size of the o/w reference without CNCs after dispersing was over 50 $\mu \mathrm{m}$ and coalescence occurred only a few minutes after the emulsifying mixing procedure. All three investigated CNCs were effective stabilizers for the o/w system (oil droplets size under 10 $\mu \mathrm{m}$ ) by preventing the oil droplet coalescence over time ( 6 weeks) and resulting in a stable creaming layer. The CNCs prepared using green DES systems boasted performance comparable to that of commercial CNCs, and they showed effectiveness at $0.1 \%$ dispersant dosage.
\end{abstract}

Keywords coalescence; dispersing agent; nanocellulose; oil spill; o/w emulsion; stability

\section{Introduction}

Various surfactants and particles have been used to promote the dispersion and stabilization of oil in water $(\mathrm{o} / \mathrm{w})$ emulsions. Dispersants or emulsifying agents (which are typically soluble compounds with amphiphilic characteristics) minimize o/w interfacial energy, thus enhancing the emulsions' long-term stability (De Gennes and Taupin 1982; Abdolmaleki et al. 2016). Inorganic or petrochemical-based particles or colloids of silica, clay, calcium carbonate, hematite, polystyrene, and microgels, ranging in size from nanometers to micrometers, can all form stable particlestabilized o/w emulsions (so-called Pickering emulsions) (Aveyard et al. 2003; Chevalier and Bolzinger 2013; Lyu et al. 2016). Pickering emulsions are abundant in nature and will become more common, for instance, in the fields of food applications (Yang et al. 2012), filled-reinforced composite materials (Wu et al. 2014), drug delivery (Fang et al. 2008), and polymer blends, because they are generally more stable against coalescence than emulsions stabilized by surfactants alone. However, mineral based nanoparticles are not commonly used in the field of oil spill response in marine environment at the moment. There are reports that for instance silica (nano)particles can be toxic to many animals (Van Hoecke et al. 2008; Elsaesser and Howard 2012; Kim et al. 2015) and due to the bioaccumulation (Yildirimer et al. 2011) they can end up even in the humans, which is highly undesirable. By contrast, many biomaterials provide an 
interesting source of biodegradable alternative, working as green dispersing agents in the form of nanoparticles. For example, cellulose nanocrystals (CNCs), which are rod-like, stiff nanoparticles derived from natural cellulose sources, (Carpenter et al. 2015) have recently been shown to stabilize different o/w emulsions. Also microfibrillated cellulose particles have been shown to stabilize o/w emulsions (Andresen and Stenius 2007; Xhanari et al. 2011). If these solid cellulose particles are added to an o/w emulsion mixture, they can bind to the oil-water interface and prevent the oil droplets from coalescing, thus causing the emulsion to be more stable (Kalashnikova et al. 2011; Kalashnikova et al. 2012; Kalashnikova et al. 2013; Hu et al. 2015a; Hu et al. 2015b; Hu et al. 2016; Ojala et al. 2016).

Chemical oil spill remediation techniques use emulsifying agents to disperse oil slicks to smaller droplets and promote the inherent biodegradability of oil by marine microbes (Prendergast and Gschwend 2014). For this purpose, bio-based cellulosic nanoparticles could be especially beneficial, because the cytotoxic effects of nanocelluloses has been found to be minor (Vartiainen et al. 2011; Bhattacharya et al. 2012; Alexandrescu et al. 2013; Hua et al. 2014; Malinen et al. 2014). Also, toxicity and biodegradability analyses indicate that nano-scale cellulose particles can be considered to be safe for living organisms (Lou et al. 2014; Pitkänen et al. 2014; Vikman et al. 2015; Ruka et al. 2015). By contrast, the safety of many synthetic dispersing agent formulations has been questioned, because of their potential negative health effects for humans and the marine ecosystem (Ramachandran et al. 2004; Ramachandran et al. 2006; Jung et al. 2009; Kujawinski et al. 2011; Zhang et al. 2013; Gong et al. 2014; DeLeo et al. 2015). Based on previous mentioned fact in the use of synthetic surfactants many countries like Finland, Sweden and England have banned many commercial available dispersing chemicals and this mean in practice that they are not even allowed to use in the Baltic and North Seas (http://www.environment.fi/en-US; Wang M. 2010). So there is need to develop novel types of environmentally safe dispersing chemicals in order to reduce the environmental impact of oil spills.

Despite functionalized nanocelluloses having shown their potential as dispersing agents in Pickering emulsions, their production requires expensive, harmful, or toxic chemicals in many cases. Consequently, new green techniques are sought to enable their sustainable production. Deep eutectic solvents (DESs) are a relatively novel class of chemicals that can function as solvents, reactants, and catalysts. DESs are often classified as ionic liquids, although they can also be obtained from non-ionic species (Wagle et al. 2014; Smith et al. 2014). Compared to ionic liquids, DESs exhibit certain advantages, such as easy preparation from two or more components without the need for separate purification steps. DESs can be obtained from readily available, bio-based, inexpensive, low-toxicity materials, which can be regenerated quite easily. Recently, the first results of DES use as a pretreatment for cellulose nanofibrillation have been reported (Sirviö et al. 2015; Sirviö et al. 2016).

The aim of this research was to investigate cellulose nanocrystals derived from a deep eutectic solvent (DES) of choline chloride and oxalic acid dihydrate as an o/w Pickering emulsion stabilizer. Two different commercially available cellulose nanocrystals (referred to as CNC-Ref1 and CNC-Ref2) were used as a reference, and their ability to serve as a marine oil dispersing agent were addressed. Natural creaming of emulsified oils was observed over time with all CNCs. Oil layer creaming is supposed to be beneficial for the purposes of oil cleaning and collecting, because a creamed oil layer is easier to skim. However, a creaming layer has been kept stable over time. Consequently, o/w creaming formation and stability of a creaming layer during storing were examined in particular.

\section{Materials \& Methods}

\subsection{Raw material and chemicals}

\subsubsection{Chemicals used}

For all o/w emulsions, lightweight marine diesel oil was used. This diesel oil was a sulphur-free winter grade with a density of $828 \mathrm{~kg} / \mathrm{m}^{3}$ at $15^{\circ} \mathrm{C}$ and viscosity of $1.846 \mathrm{~mm}^{2} / \mathrm{s}$ at $40^{\circ} \mathrm{C}$ (Neste Oyj, Finland). Conductivity of the marine diesel oil was very low: $0.073 \mu \mathrm{S} / \mathrm{cm}$ at $20^{\circ} \mathrm{C}$.

All chemicals were pro analysis grade and used without further purification. In dilutions and disintegrations, deionized water was used throughout the experiments. Dissolving pulp (softwood) was used as a raw material for production of 
DES-treated cellulose. The cellulose, lignin, and hemicelluloses content of the dissolving pulp was 96.2, 3.5, and $<0.5 \%$, respectively. Pulp was obtained as dry sheets and was used after disintegration in water. Disintegrated pulp was filtered, washed with ethanol, and dried at $60^{\circ} \mathrm{C}$ for 24 hours. Choline chloride and oxalic acid dihydrate were obtained from Sigma Aldrich (Germany).

\subsubsection{Cellulose nanocrystals from DES treatment Chemical treatment of dissolved cellulose}

DES was produced by mixing $63.06 \mathrm{~g}$ of choline chloride and $56.94 \mathrm{~g}$ of oxalic acid dihydrate at $100^{\circ} \mathrm{C}$ for approximately 30 minutes. When a clear solution was obtained, $1.2 \mathrm{~g}$ of dissolving pulp ( softwood) was added, and the suspension was mixed for 6 hours. Reaction was quenched by addition of $100 \mathrm{ml}$ of deionized water before the solution was filtered and finally washed with $400 \mathrm{ml}$ of deionized water.

\section{Liberation of nanocrystals from DES-treated cellulose}

The DES-treated dissolved cellulose material was converted to individual nanocrystals at a solids content of $0.5 \mathrm{wt} \%$ and a $\mathrm{pH}$ of 7 ( $\mathrm{pH}$ was adjusted using a dilute $\mathrm{NaOH}$-solution) using a homogenization treatment with $\mathrm{M}-110 \mathrm{EH}-30$ microfluidizer (Microfluidics, U.S.A.). Suspension was passed three times through a $400 \mu \mathrm{m}$ auxiliary processing module (APM) and a $200 \mu \mathrm{m}$ interaction chamber (IXC) at a pressure of 1300 bar. Afterward, the suspensions were passed three times through a combination of $400 \mu \mathrm{m}$ APM and $87 \mu \mathrm{m} \mathrm{IXC} \mathrm{at} \mathrm{a} \mathrm{pressure} \mathrm{of} 2000$ bar. The obtained CNC suspensions were clear and only slightly viscous. Samples were marked as DES-CNC.

\subsubsection{Reference cellulose nanocrystals}

Two commercial CNC suspensions named BGB natural (CNC-Ref1) and BGB ultra (CNC-Ref2) were purchased from Blue Goose Biorefineries Inc., Canada. Acetate-grade dissolving pulp (western hemlock) was used as a raw material for BGB's CNC fabrication. BGB production process is oxidative in nature and does not involve acid hydrolysis. However, the process resulting similar size and charge to acid hydrolysis CNC but does not contain any sulfate half esters. BGB Inc. use R $3^{\mathrm{TM}}$ technology (patent pending) allowing green chemistry to manufacture renewable plant biomass into individual CNCs. Washing with deionized water and concentration with ultrafiltration were the only treatments of the product after manufacturing. Both $\mathrm{CNC}$ reference suspensions were delivered in approximately $7 \%$ consistency and were instantly usable and dispersible to water. CNC gels from CNC-Refl were slightly thicker and more opaque than CNC-Ref2.

\subsection{Characterization of cellulose nanocrystals}

\subsubsection{Transmission electron microscopy (TEM)}

The morphological features of DES-CNC and two commercial CNCs (CNC-Ref1 and CNC-Ref2) were analyzed with a Tecnai G2 Spirit transmission electron microscope (FEI Europe, Eindhoven, the Netherlands). Samples were prepared by diluting each nanocellulose suspension with Milli-Q water. A small droplet of the dilution was deposited on top of a carbon-coated copper grid, and excess sample was removed from the grid by touching the droplet with the corner of a filter paper. The samples were negatively stained by placing a droplet of uranyl acetate $(2 \% \mathrm{w} / \mathrm{v})$ on top of each specimen. The excess uranyl acetate was removed with filter paper as described earlier. The grids were dried at room temperature and analyzed at $100 \mathrm{kV}$ under standard conditions. Images were captured with a Quemesa CCD camera, and iTEM image analysis software (Olympus Soft Imaging Solutions GMBH, Munster, Germany) was used to measure the width and length of the individual particles. 


\subsubsection{X-ray diffraction (XRD)}

The crystalline structure of the different CNCs was investigated using wide-angle X-ray diffraction (WAXD) and determined based on the Segal method (Segal et al. 1959). Measurements were conducted on a Rigaku SmartLab $9 \mathrm{~kW}$ rotating anode diffractometer (Japan) using Co K $\alpha$ radiation source $(40 \mathrm{kV}, 135 \mathrm{~mA})(\lambda=0.179030 \mathrm{~nm})$. Samples were prepared by pressing tablets of freeze-dried celluloses to a thickness of $1 \mathrm{~mm}$. Scans were taken over a $2 \theta$ (Bragg angle) range from $5^{\circ}$ to $50^{\circ}$ at a scanning speed of $10^{\circ} / \mathrm{min}$, using a step of $0.05^{\circ}$. The degree of crystallinity in terms of the crystallinity index (CrI) was calculated from the peak intensity of the main crystalline plane (200) diffraction $\left(\mathrm{I}_{200}\right)$ at $26.1^{\circ}$ and from the peak intensity at $22.0^{\circ}$ associated with the amorphous fraction of cellulose ( $\mathrm{I}_{\mathrm{am}}$ ) (French 2014). The degree of crystallinity is calculated by Equation 1 .

$\operatorname{Crl}=\frac{I_{200}-I_{a m}}{I_{200}} \times 100 \%$

It should be noted that due to the Co Ka radiation source used, the cellulose peaks have different diffraction angles compared to results obtained by a $\mathrm{Cu} \mathrm{K} \alpha$ radiation source.

\subsection{Preparation of $\mathrm{o} / \mathrm{w}$ emulsion}

The marine diesel o/w emulsions were prepared using the UltraTurrax mixer (IKA T25, Germany) at 7000 rpm for 15 min. The ratio of oil and water was 1:10 throughout the study. The $0.1 \%(\mathrm{wt}) \mathrm{CNC}$-solution was diluted into the water phase before oil was added and dispersed. Sodium chloride $(\mathrm{NaCl})$ was used as a background electrolyte at concentration of $1 \mathrm{w} / \mathrm{w}-\%$ (equivalent to the salinity of $171 \mathrm{mmol} / \mathrm{l}$ ). Salt concentration was used to simulate the effect of salinity (comparable to sea water salinity in the Baltic Sea) on dispersion stability and oil droplet size. As a reference, pure o/w emulsion without the $\mathrm{CNC}$ addition was used.

\subsection{Laser diffraction particle size analyzer}

The changes in volumetric oil-droplet size distributions were measured with the laser diffraction particle size analyzer (LS 13 320, Beckman Coulter, U.S.A.). Each sample was measured directly after dispersing and over time (in the case of the stability measurement). The method enables droplet diameters from $0.04 \mu \mathrm{m}$ to $2000 \mu \mathrm{m}$ to be measured. The mean droplet diameter was taken to be the volume mean diameter from 3 replicate measurements.

The 'span' was taken as a measurement of the width of the particle size distribution. It is calculated using span = $(\mathrm{D}(0.9)-\mathrm{D}(0.1) / \mathrm{D}(0.5)$, where $\mathrm{D}(0.9)$ is the droplet diameter for which $90 \%$ of the droplets lie below this size, $\mathrm{D}(0.5)$ is the droplet diameter for which $50 \%$ of the droplets are below this size, and $\mathrm{D}(0.1)$ is the diameter for which only $10 \%$ of the droplets are smaller than this size. The stability of emulsions was also evaluated by monitoring the emulsion droplet diameter over 6 weeks with the Beckman Coulter particle size analyzer.

\subsection{CCD camera unit}

The dispersed oil droplets in the flowing oil-water suspension were visualised with a high-definition CCD camera unit which captured approximately 1000 individual pictures including between 100,000-200,000 individual oil droplets per sample. The method itself has been described in more detail previous publications (Haapala et al. 2013; Kangas et al. 2014; Laitinen and Niinimaki 2014). Image analysis of individual particles was accomplished by applying a sub-pixel algorithm resulting in resolution of around $1 \mu \mathrm{m}$. In this study, minimum particle size analyzed was set to be $3 \mu \mathrm{m}$ to ensure that only oil droplets were included in the measurement. The photographs obtained with the CCD camera were used to evaluate the particle size distribution based on the projected oil-droplet area diameter. 


\section{Results and Discussion}

\subsection{Characterization of cellulose nanocrystals}

According to TEM images (Figure1), all the nanocelluloses that were used existed as rod-like cellulose nanocrystals. The width of individual crystals typically varied from 3-8 nm, while their length ranged from 50 to $350 \mathrm{~nm}$, according to the image analysis. It seems that commercial crystals (CNC-Ref1 and CNC-Ref2) were similar in size to DES-treated crystals despite use of different wood species (western hemlock vs. European softwood) and fabrication processes (oxidation vs. DES treatment). The size distributions were in line with many earlier studies (Visanko et al. 2014; Laitinen et al. 2014; Laitinen et al. 2016). All nanocrystals seemed to be well-individualized from each other without the formation of larger aggregates. Moreover, all suspensions remained stable during usage and storage.

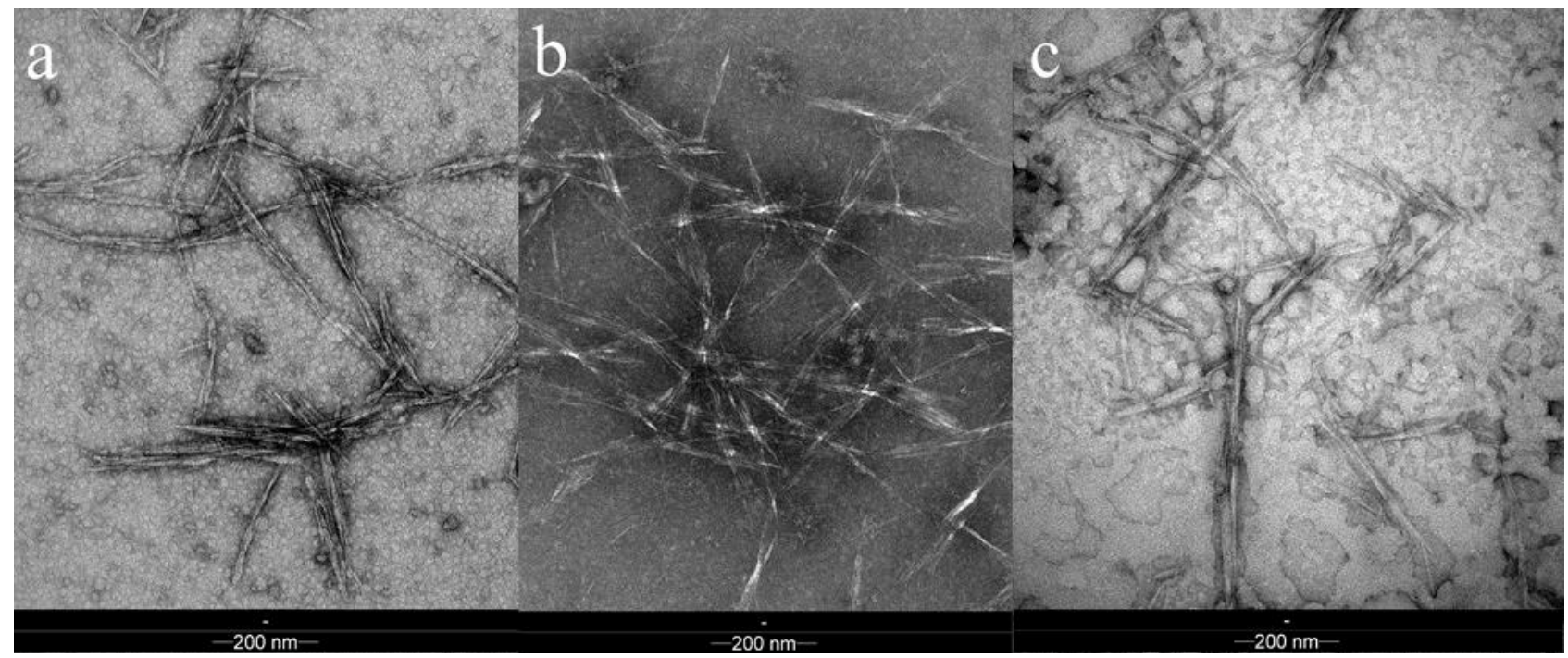

Fig. 1 Example of TEM images of a) CNC-Ref1 b) CNC-Ref2 and c) DES-CNC.

Based on WAXD analysis, all of the CNCs retained their cellulose I crystalline structure, exhibiting the main $2 \theta$ diffraction angles close to $18.0^{\circ}, 22.0^{\circ}$, and $26.1^{\circ}$ associated with the (1-10), (110), and (200) crystalline planes. The crystallinity indexes calculated according to Eq. 1 for DES-CNC, CNC-Refl, and CNC-Ref2, were 68\%, 70\%, and 67\%, respectively. The original dissolving pulp (softwood) has CrI of 67\%. X-ray diffraction patterns of different nanocelluloses are presented in Figure 2. 


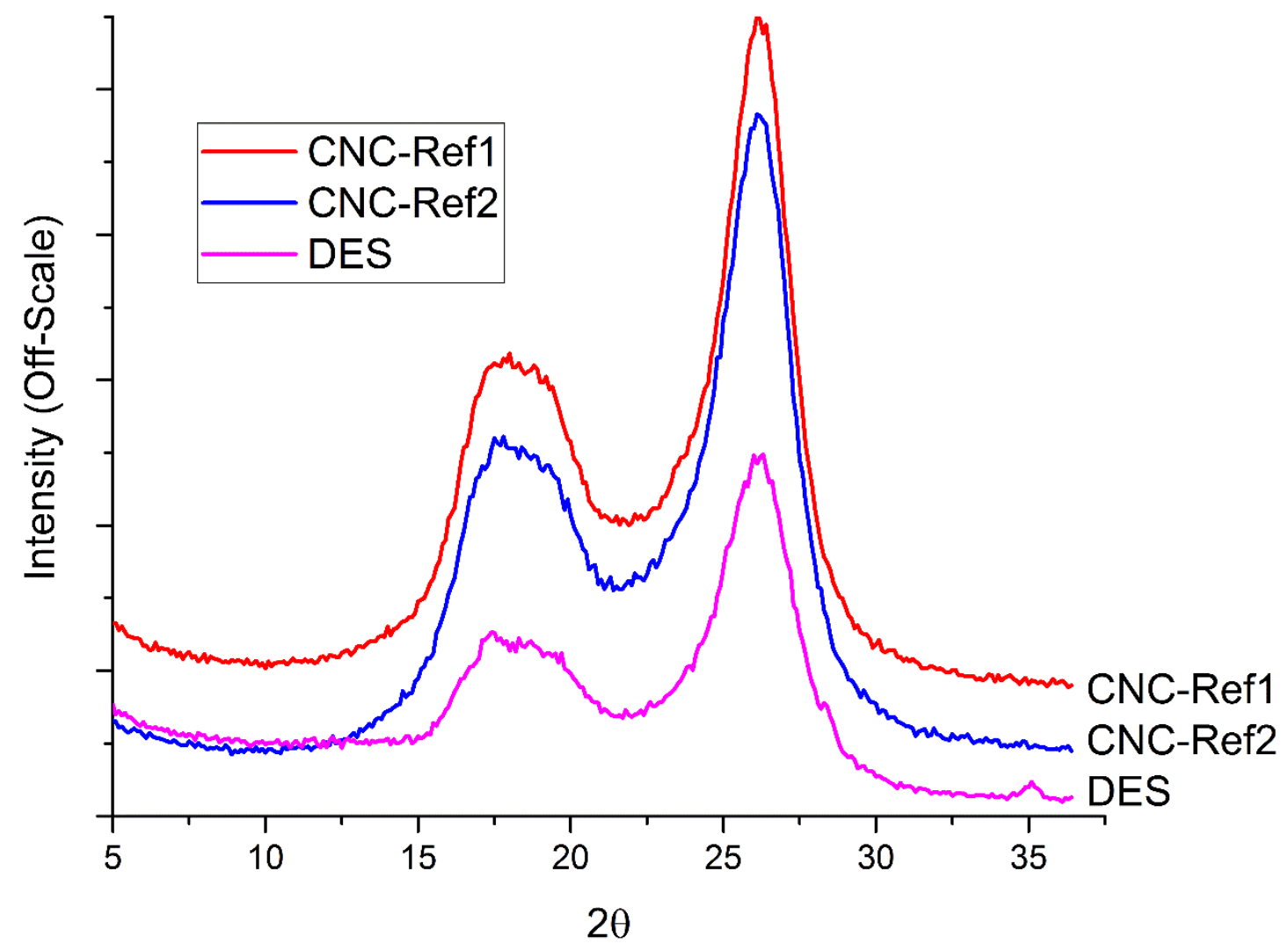

187 Fig. 2 X-ray diffraction patterns of different nanocelluloses.

The carboxyl content of CNCs was analysed by conductometric titration using a procedure described by Katz et al. and Rattaz et al (Katz et al. 1984; Rattaz et al. 2011). The carboxyl contents and conductivities of CNC samples are presented in Table 1. The DES-CNC had a carboxylic acid contents of $0.23 \mathrm{mmol} \mathrm{g}^{-1}$ while the reference $C N C 1$ and CNC 2 had values of $0.09 \mathrm{mmol} \mathrm{g}^{-1}$ and $0.15 \mathrm{mmol} \mathrm{g}^{-1}$, respectively. Therefore, all CNCs had a relative low surface charge density, which likely decreased their hydrophilicity (compared to, for instance, acid hydrolysed CNCs) and improved their potential as effective emulsion stabilizers (Kalashnikova et al. 2011; Kalashnikova et al. 2012; Kalashnikova et al. 2013). On the other hand, the small surface charge density was enough to prevent the inherent aggregation tendency of CNCs and the samples remained stable during storage. Conductivity variations between different samples were likely affected mainly due to small amount of impurities in dilution water. DES-CNC has been diluted with deionized laboratory water while commercial CNCs (CNC-Ref1 and CNC-Ref2) contain tap water and that is why conductivities were slightly higher. 
Table 1 Characteristics of CNC samples. Carboxyl content, type of emulsion, mean droplet diameter and "span" (measured by LS 13320 Beckman Coulter) for fresh diesel oil emulsions stabilized by $0.1 \mathrm{wt}-\%$ CNCs. (The span is calculated as described in Chapter 2.4.).

\begin{tabular}{|c|c|c|c|c|c|c|}
\hline Dispersant & Abbreviation & $\begin{array}{l}\text { Carboxyl } \\
\text { content } \\
(\mathrm{mmol} / \mathrm{g})\end{array}$ & $\begin{array}{l}\text { Conductivity } \\
(\mu \mathrm{S} / \mathrm{cm})\end{array}$ & $\begin{array}{l}\text { Type of } \\
\text { emulsion }\end{array}$ & $\begin{array}{l}\text { Mean } \\
\text { diameter } \\
{[\mu \mathrm{m}]}\end{array}$ & Span \\
\hline$D E S-C N C$ & DES & 0.23 & 130 & $\mathrm{o} / \mathrm{w}$ & 9.3 & 2.26 \\
\hline BGB natural & CNC-Ref1 & 0.09 & 286 & $\mathrm{o} / \mathrm{w}$ & 7.2 & 1.54 \\
\hline$B G B$ ultra & CNC-Ref2 & 0.15 & 369 & $\mathrm{o} / \mathrm{w}$ & 7.0 & 1.69 \\
\hline Reference o/w & REF & - & - & not stable & 52.3 & 4.34 \\
\hline
\end{tabular}

\subsection{O/w Pickering emulsions stabilized by different CNCs}

The efficiency of dispersing agents in o/w emulsification is affected by temperature, mixing energy, and water electrolyte concentration (salinity) (Chandrasekar et al. 2006). As a conclusion of our recently published article, (Ojala et al. 2016) we selected in this study constant conditions in terms of mixing, temperature, and background electrolyte concentration (described in Chapter 2.3) in order to compare all different CNC dispersants in the same emulsification conditions. Conductivity and $\mathrm{pH}$ of freshly prepared o/w emulsions were $10.9 \mathrm{mS} / \mathrm{cm}$ and 7.3 , respectively, for all investigated samples. Conductivity originated mainly due to salinity of background solution.

Figure 3 presents the o/w emulsions and creaming layers 4 hours after emulsification in the presence and absence of CNCs. Clearly, the reference sample without dispersant was not stable and coalescence was easily observed over time. All CNC-stabilized emulsions formed natural smooth creaming layers. However creaming are still on progress after 4 hours. The volume of original oil layer was $6.5 \mathrm{ml}$ before emulsification and was again $6.5 \mathrm{ml} 4$ hours after emulsification without $\mathrm{CNC}$ use. The $D E S-C N C$ cream layer volume was $19.4 \mathrm{ml} 4$ hours after emulsification, while the reference CNC-Ref1 and CNC-Ref2 had values of $20.5 \mathrm{ml}$ and $19.4 \mathrm{ml}$, respectively. Thus, the volumes of creaming layers were around three times larger in the presence of $\mathrm{CNCs}$, compared to oil layers without any dispersant. 


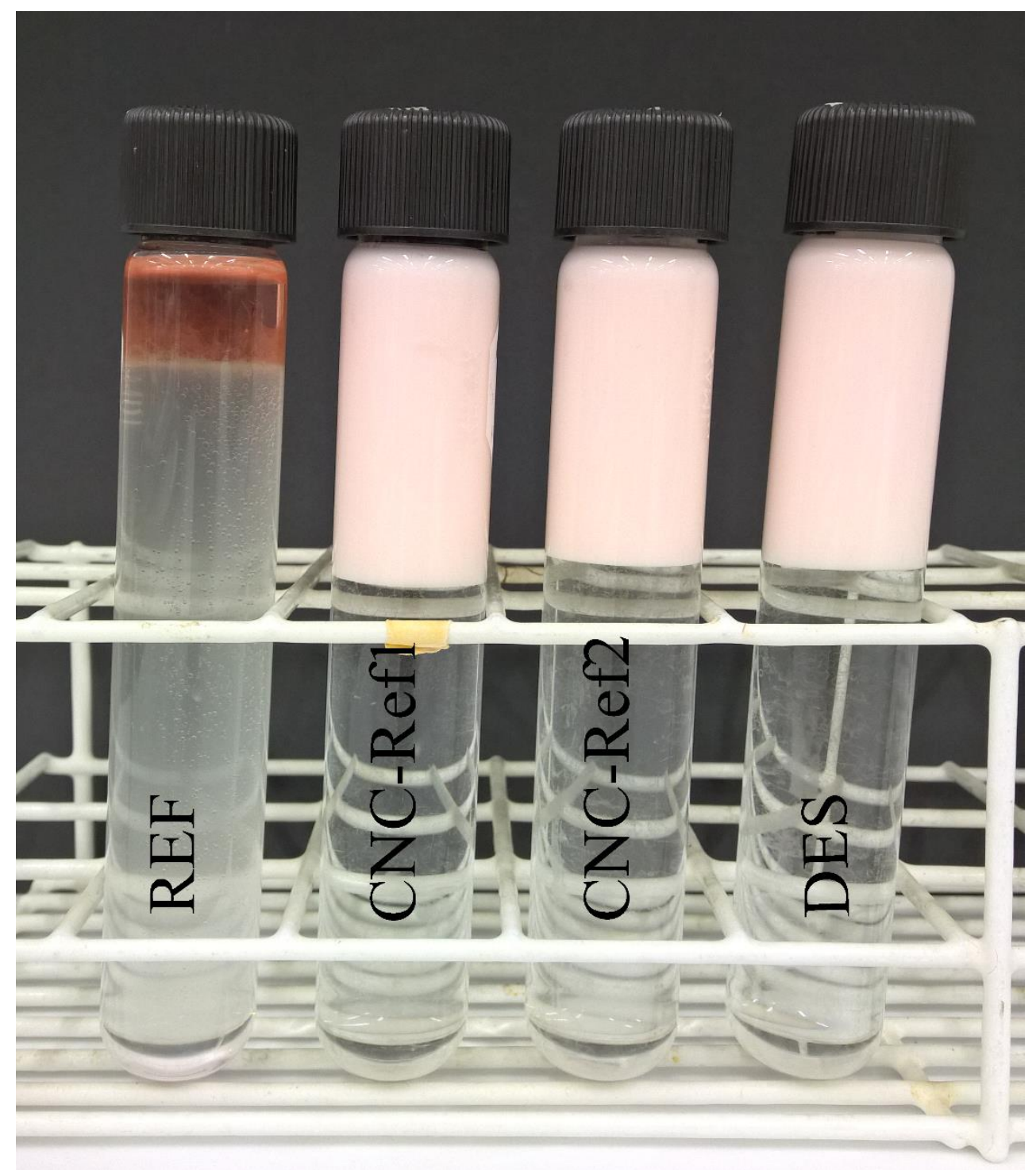

Fig. 3 Example of o/w emulsions and creaming layers 4 hours after emulsification in the presence of CNC dispersant and the absence of dispersant. From left: o/w emulsion without CNC, o/w with CNC-Ref1, CNC-Ref2 and CNC-DES.

Figure 4 presents kinetics of oil emulsion creaming when using different CNC dispersants. Formation of a cream layer was fastest during the first two hours after emulsification and was the fastest with the CNC-Refl, while the DES-CNC and the $C N C$-Ref2 showed slightly slower kinetics. In practice, volumes of cream layers reached a constant level 1 week after emulsification and after that only minor changes happened. The DES-CNC cream layer volume was $14.4 \mathrm{ml} 10$ weeks after emulsification, while the reference CNC-Ref1 and CNC-Ref2 had values of $14.4 \mathrm{ml}$ and $12.5 \mathrm{ml}$, 231 respectively. 


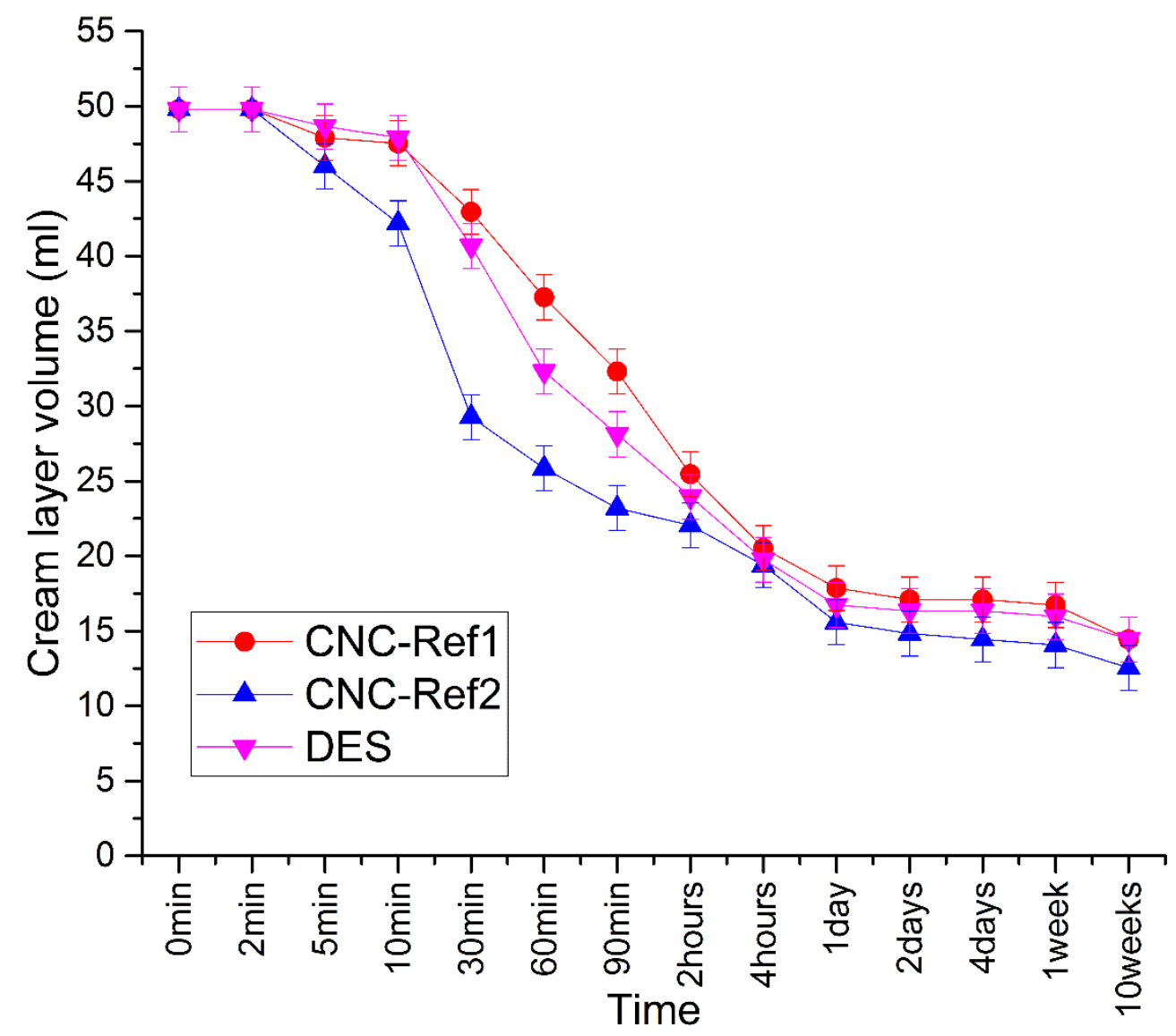

Fig. 4 Kinetics of oil emulsion creaming with different CNC dispersants. Error bars represents standard deviation of three replicates.

\subsubsection{Laser diffraction particle size analyzer}

A laser diffraction particle size analyzer was used to determine the average oil-droplet particle size in the marine diesel o/w emulsions stabilized by CNCs. In Table 1, type of emulsion, the mean particle diameter and "span" values of fresh emulsions stabilized by CNCs are presented.

Stabilization of emulsion with different CNCs resulted in a significant reduction in oil-droplet size compared to o/w emulsion without any dispersant. The particle size of the o/w reference without CNCs was approximately $52.3 \mu \mathrm{m}$ and span value was 4.34 , indicating very wide size distribution. This emulsion was not stable, and coalescence had already occurred some minutes after the emulsifying mixing procedure. However, all CNC-stabilized emulsions had mean droplet size less than $10 \mu \mathrm{m}$, and they remained stable for a long period (Figure 7).

\subsubsection{CCD camera unit}

Oil droplets were visualised with a high-definition CCD camera unit as described in Chapter 2.6. Figure 5 shows example pictures of oil droplets after emulsification $(2 \mathrm{~min})$. Use of CNCs resulted in a significant reduction in oildroplet sizes compared to o/w emulsion without any dispersant. The imaging method is very suitable for analysis of oil droplets, because droplets are round and of proper size, and contrast between background and oil droplets is clear (i.e.,

251 grey vs. black). 

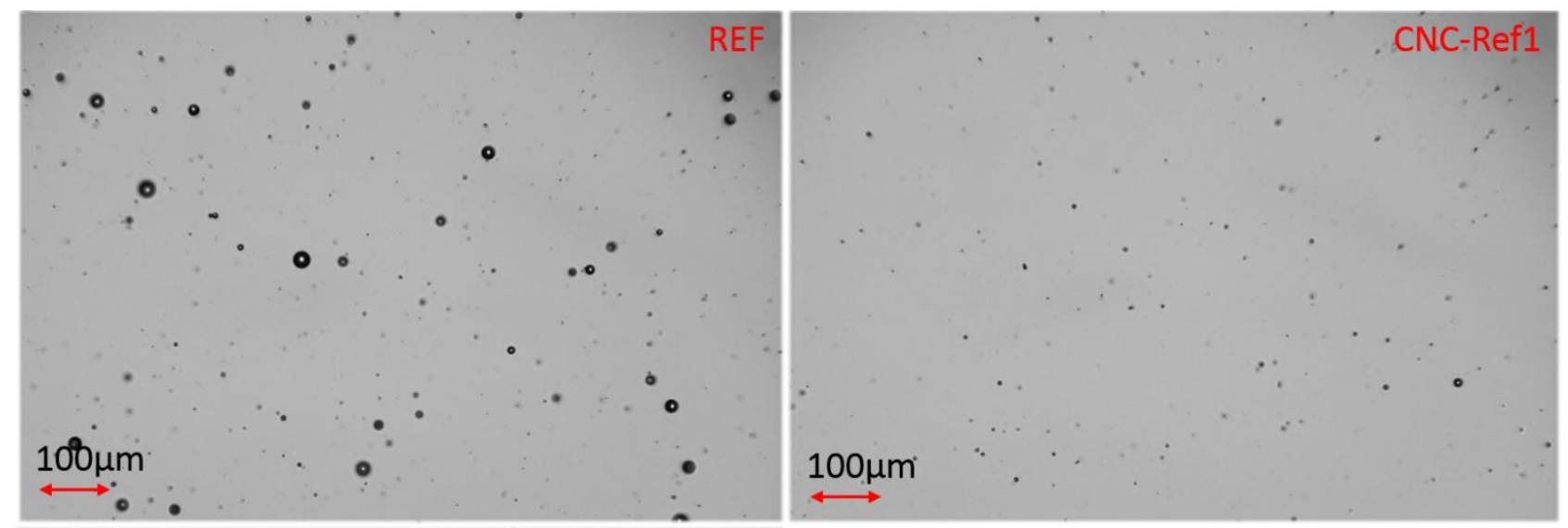

CNC-Réf2

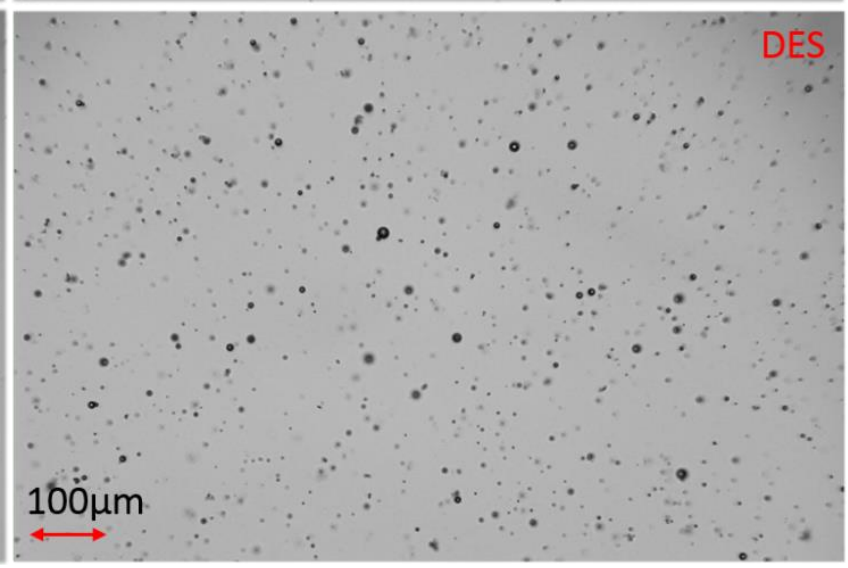

Fig. 5 Example pictures of oil droplets after emulsification visualized by a high-definition $\mathrm{CCD}$ camera unit. (REF = $\mathrm{o} / \mathrm{w}$ emulsion without CNC and CNC-Ref1/CNC-Ref2/CNC-DES = o/w emulsion stabilized with CNC-Ref1, CNCRef2 and CNC-DES).

The photographs obtained with the CCD camera after emulsification (2 min) were analyzed and particle size distribution of oil droplets are presented in Figure 6. Over 100,000 individual oil droplets have been analyzed per sample. The particle size distribution of the o/w reference after dispersing was seen to be much broader than with CNCstabilized emulsions. DES-CNC had slightly broader particle size distribution than CNC-Refl or CNC-Ref2. All these observations are well in line with results measured by LS 13320 Beckman Coulter (Table 1). 


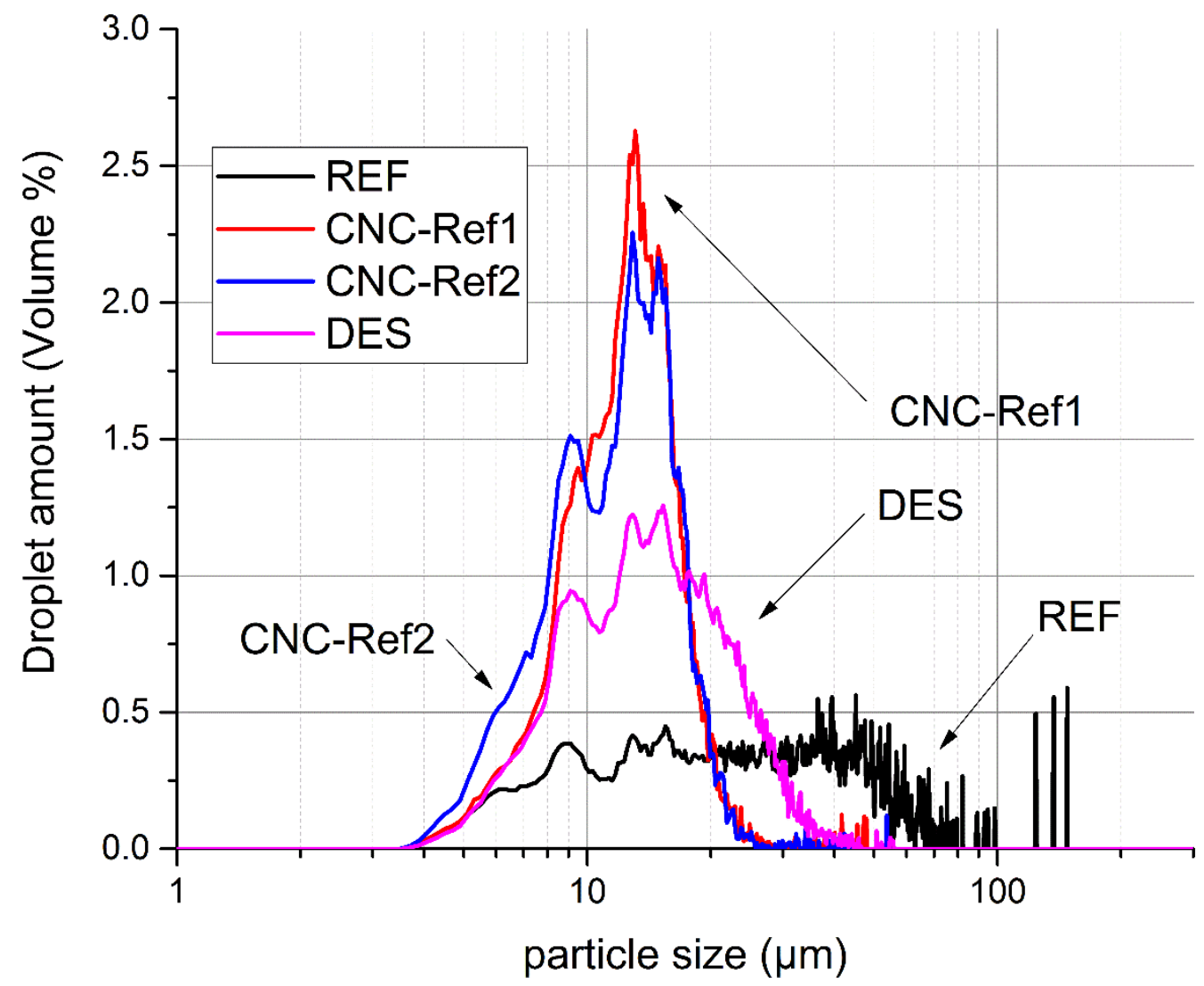

Fig. 6 Size distributions of oil droplet from o/w emulsions stabilized by CNCs. Minimum particle size included in image analysis was $3 \mu \mathrm{m}$.

\subsection{Emulsions stability}

An emulsion is commonly considered to be stable if it is resistant to physical changes over a practical length of time. As marine diesel oil has a lower density than water $\left(\mathrm{d}=828 \mathrm{~kg} / \mathrm{m}^{3}\right.$ at $\left.15^{\circ} \mathrm{C}\right)$, a creaming process was always observed. Despite the formation of a creaming layer, no droplet coalescence occurred; that is, the size and size distribution of o/w emulsion was not notably changed.

The long-term stability of o/w emulsions stabilized by CNCs (1:10) in terms of oil cream droplet coalescence was assessed by measuring the change in mean droplet size over time using a particle size analyzer (LS 13 320, Beckman Coulter). Stability results are presented in the Figure 7. The stability of the reference o/w emulsion without CNCs was poor, as already noted and discussed in the droplet-size measurement or visual observation, and significant coalescence started immediately after emulsifying procedure. 


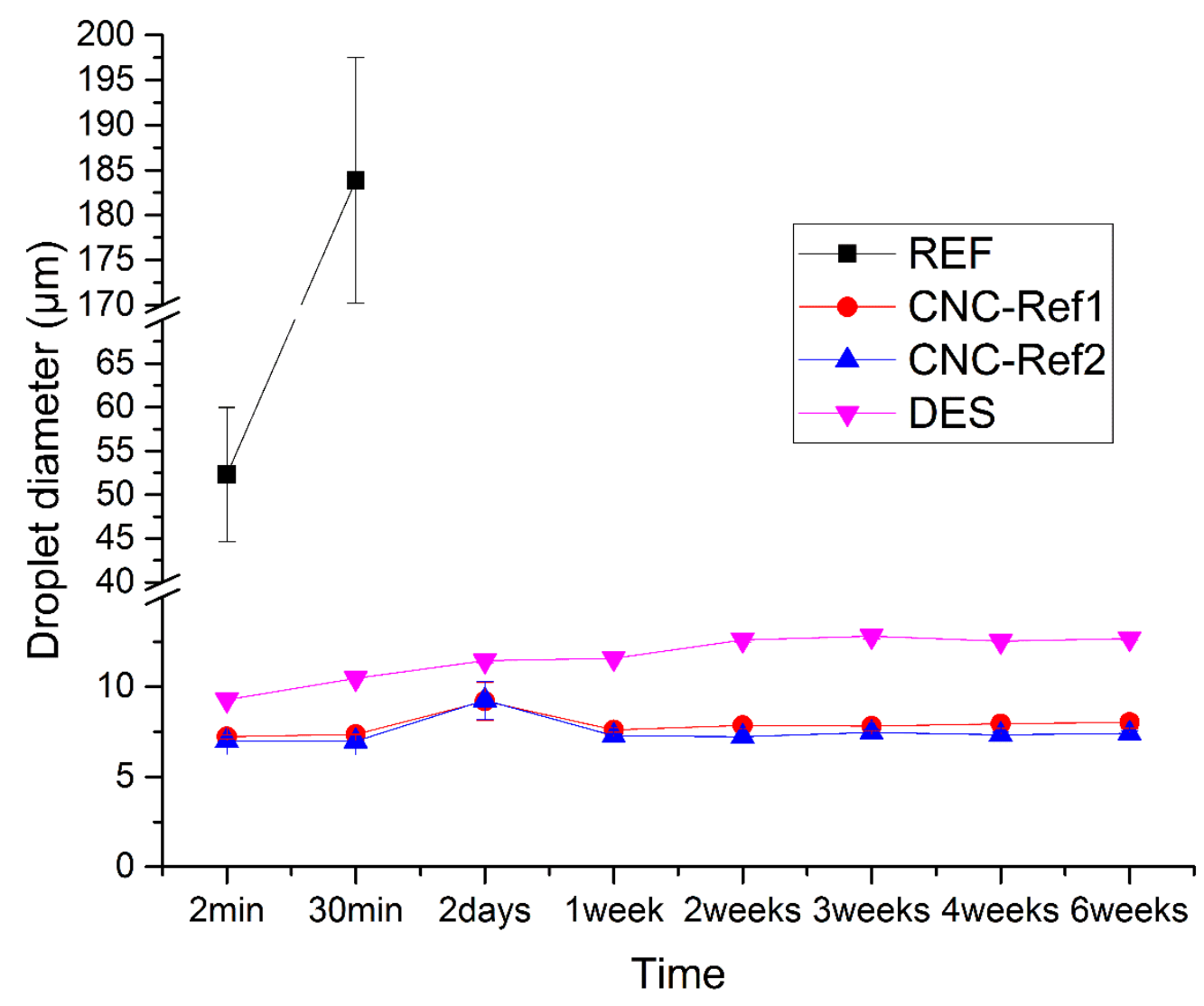

Fig. 7 Average droplet diameter o/w emulsions stabilized by CNCs cream emulsions over 6 weeks. Error bars represents standard deviation of three replicates.

Figure 7 shows that Pickering emulsions of CNC-Ref1 and CNC-Ref2 are extremely stable against coalescence, with minimal change in droplet size over 6 weeks, although natural creaming occurred. The CNC-Refl emulsions, which had the smallest droplet sizes at the beginning, exhibit the least coalescence. Only minor droplet size increases occurred with DES-CNC emulsions, indicating stable emulsion (over 6 weeks' storage), which should be enough for collecting (i.e., skimming) stabilized oil in the case of an oil spill. When oil in water emulsion is skimmed away from the surface of water, it means in practice that only minor part of CNCs will be remain in the water.

Additionally, stability of all CNC Pickering emulsions were tested by shaking the samples regularly. As a result of shaking tests, all emulsions reformed stable creaming layers after a few hours, so they acted the same way as they had after the initial emulsification procedure. This phenomenon is beneficial especially for oil collecting, where a creaming layer may be exposed by wave action that tends to break up the stabilized o/w layer.

Stability of prepared emulsions was analyzed by centrifugation of samples for $5 \mathrm{~min}$ at $2415 \mathrm{G}$ for analyzing the resistance of droplets to coalescence. The $\mathrm{o} / \mathrm{w}$ emulsions after centrifugation in the presence of CNCs are shown in Figure 8. All CNC-stabilized emulsions were stable after centrifugation and coalescence were not observed, i.e. no visible oil layer appeared on the surface of the emulsions. 


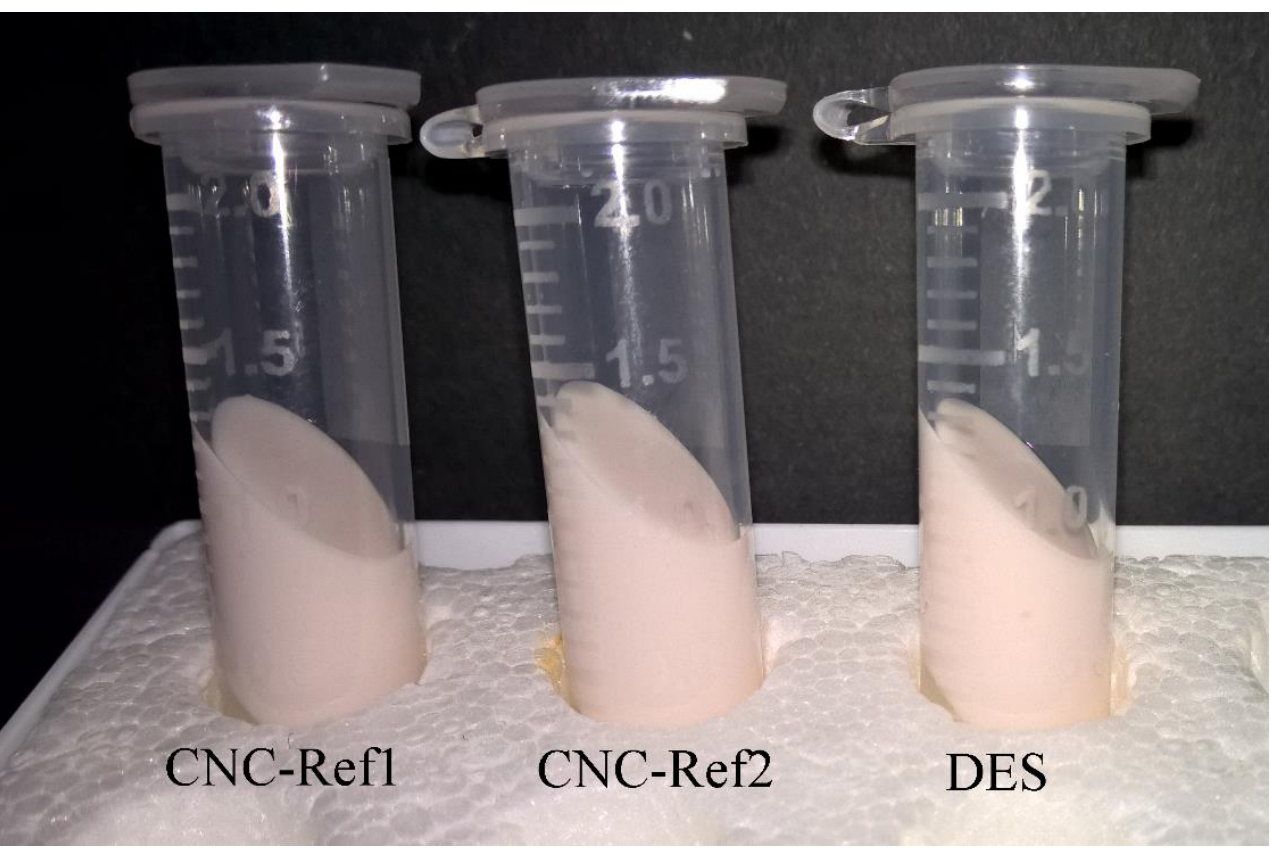

Fig. 8 Example of o/w emulsions after centrifugation in the presence of CNC dispersant. From left: o/w with CNC-Refl, CNC-Ref2 and CNC-DES.

\subsection{Stabilization of o/w Pickering emulsion by adsorbed CNCs}

The surface coating by solid particles mainly acts against emulsified droplet coalescence. The adsorbed layer of CNCs likely forms a rigid layer around the oil droplets as previously shown (Kalashnikova et al. 2011; Jiang and Hsieh 2015; $\mathrm{Hu}$ et al. 2015b). Therefore, the reorganization of the surface layer required for oil droplets to merge is prevented by a mechanical barrier. Nanocellulose particles are held together at the oil-water interface by means of attractive interactions created by hydrogen bonding while capillary forces force particles to be adsorbed at the o/w liquid-liquid interface. As it can be assumed, the strong adhesion of CNCs to the interface confers high resistance to coalescence and high stability to the emulsion. This will be attributed to the particular behavior of cellulosic particles, that is, their elongated shape and the low surface charge density chemistry forming a network of isolated oil droplets covered by nanocrystals.

\section{Conclusions}

The CNCs fabricated in Deep eutectic solvents were successfully used as novel biochemical for aqueous Pickering emulsification of marine diesel oil. All investigated CNCs were both effective and stable emulsifier in o/w system and they reduced the oil-droplet size significantly in emulsions. The performance of DES-CNCs was comparable to that of commercial CNCs and they showed effectiveness at $0.1 \%$ dispersant dosage. The emulsions which have the smallest droplet sizes at the beginning exhibit the least coalescence. The complexity of the interactions between novel cellulosebased nanoparticle surfactants and different oil types is evident and thus more experiments related to the oil and dispersant dosage including emulsification energy are needed in order to complete the lack of statistical data on this issue.

\section{Acknowledgements}

This work was conducted as part of the ERDF-funded VIKE project ("Improvement of the oil spill prevention and response with the green chemicals") and also financed by the Academy of Finland ("Arcrespo project"). We 


\section{References}

Abdolmaleki K, Mohammadifar MA, Mohammadi R, et al (2016) The effect of $\mathrm{pH}$ and salt on the stability and physicochemical properties of oil-in-water emulsions prepared with gum tragacanth. Carbohydr Polym 140:342-348. doi: 10.1016/j.carbpol.2015.12.081

Alexandrescu L, Syverud K, Gatti A, Chinga-Carrasco G (2013) Cytotoxicity tests of cellulose nanofibril-based structures. Cellulose 20:1765-1775. doi: 10.1007/s10570-013-9948-9

Andresen M, Stenius P (2007) Water-in-oil Emulsions Stabilized by Hydrophobized Microfibrillated Cellulose. J Dispers Sci Technol 28:837-844. doi: 10.1080/01932690701341827

Aveyard R, Binks BP, Clint JH (2003) Emulsions stabilised solely by colloidal particles. Adv Colloid Interface Sci 100:503-546.

Bhattacharya M, Malinen MM, Lauren P, et al (2012) Nanofibrillar cellulose hydrogel promotes threedimensional liver cell culture. J Controlled Release 164:291-298. doi: 10.1016/j.jconrel.2012.06.039

Carpenter AW, de Lannoy C-F, Wiesner MR (2015) Cellulose Nanomaterials in Water Treatment Technologies. Environ Sci Technol 49:5277-5287. doi: 10.1021/es506351r

Chandrasekar S, Sorial G, Weaver J (2006) Dispersant effectiveness on oil spills - impact of salinity. ICES J Mar Sci 63:1418-1430. doi: 10.1016/j.icesjms.2006.04.019

Chevalier Y, Bolzinger M-A (2013) Emulsions stabilized with solid nanoparticles: Pickering emulsions. Colloids Surf Physicochem Eng Asp 439:23-34. doi: 10.1016/j.colsurfa.2013.02.054

De Gennes PG, Taupin C (1982) Microemulsions and the flexibility of oil/water interfaces. J Phys Chem 86:2294-2304.

DeLeo DM, Ruiz-Ramos DV, Baums IB, Cordes EE (2015) Response of deep-water corals to oil and chemical dispersant exposure. Deep Sea Res Part II Top Stud Oceanogr. doi: 10.1016/j.dsr2.2015.02.028

Elsaesser A, Howard CV (2012) Toxicology of nanoparticles. Adv Drug Deliv Rev 64:129-137. doi: 10.1016/j.addr.2011.09.001

Fang Y, Wang L, Li D, et al (2008) Preparation of crosslinked starch microspheres and their drug loading and releasing properties. Carbohydr Polym 74:379-384. doi: 10.1016/j.carbpol.2008.03.005

French AD (2014) Idealized powder diffraction patterns for cellulose polymorphs. Cellulose 21:885-896. doi: 10.1007/s10570-013-0030-4

Gong Y, Zhao X, Cai Z, et al (2014) A review of oil, dispersed oil and sediment interactions in the aquatic environment: Influence on the fate, transport and remediation of oil spills. Mar Pollut Bull 79:1633. doi: 10.1016/j.marpolbul.2013.12.024

Haapala A, Laitinen O, Karinkanta P, et al (2013) Optical characterisation of size, shape and fibrillarity from microfibrillar and microcrystalline cellulose, and fine ground wood powder fractions. Appita J J Tech Assoc Aust N Z Pulp Pap Ind 66:331.

Hu Z, Ballinger S, Pelton R, Cranston ED (2015a) Surfactant-enhanced cellulose nanocrystal Pickering emulsions. J Colloid Interface Sci 439:139-148. doi: 10.1016/j.jcis.2014.10.034 
Hu Z, Marway HS, Kasem H, et al (2016) Dried and Redispersible Cellulose Nanocrystal Pickering Emulsions. ACS Macro Lett 5:185-189. doi: 10.1021/acsmacrolett.5b00919

Hu Z, Patten T, Pelton R, Cranston ED (2015b) Synergistic Stabilization of Emulsions and Emulsion Gels with Water-Soluble Polymers and Cellulose Nanocrystals. ACS Sustain Chem Eng 3:1023-1031. doi: 10.1021/acssuschemeng.5b00194

Hua K, Carlsson DO, Ålander E, et al (2014) Translational study between structure and biological response of nanocellulose from wood and green algae. RSC Adv 4:2892-2903. doi: 10.1039/C3RA45553J

Jiang F, Hsieh Y-L (2015) Holocellulose Nanocrystals: Amphiphilicity, Oil/Water Emulsion, and SelfAssembly. Biomacromolecules 16:1433-1441. doi: 10.1021/acs.biomac.5b00240

Jung JH, Yim UH, Han GM, Shim WJ (2009) Biochemical changes in rockfish, Sebastes schlegeli, exposed to dispersed crude oil. Comp Biochem Physiol Part C Toxicol Pharmacol 150:218-223. doi: 10.1016/j.cbpc.2009.04.009

Kalashnikova I, Bizot H, Bertoncini P, et al (2013) Cellulosic nanorods of various aspect ratios for oil in water Pickering emulsions. Soft Matter 9:952-959. doi: 10.1039/C2SM26472B

Kalashnikova I, Bizot H, Cathala B, Capron I (2011) New Pickering Emulsions Stabilized by Bacterial Cellulose Nanocrystals. Langmuir 27:7471-7479. doi: 10.1021/la200971f

Kalashnikova I, Bizot H, Cathala B, Capron I (2012) Modulation of Cellulose Nanocrystals Amphiphilic Properties to Stabilize Oil/Water Interface. Biomacromolecules 13:267-275. doi: 10.1021/bm201599j

Kangas H, Lahtinen P, Sneck A, et al (2014) Characterization of fibrillated celluloses. A short review and evaluation of characteristics with a combination of methods. Nord Pulp Pap Res J 29:129-143.

Katz S, Beatson RP, Scallan AM (1984) The determination of strong and weak acidic groups in sulfite pulps. Sven Papperstidning R48-R53.

Kim I-Y, Joachim E, Choi H, Kim K (2015) Toxicity of silica nanoparticles depends on size, dose, and cell type. Nanomedicine Nanotechnol Biol Med 11:1407-1416. doi: 10.1016/j.nano.2015.03.004

Kujawinski EB, Kido Soule MC, Valentine DL, et al (2011) Fate of Dispersants Associated with the Deepwater Horizon Oil Spill. Environ Sci Technol 45:1298-1306. doi: 10.1021/es103838p

Laitinen O, Hartmann R, Sirviö JA, et al (2016) Alkyl aminated nanocelluloses in selective flotation of aluminium oxide and quartz. Chem Eng Sci 144:260-266. doi: 10.1016/j.ces.2016.01.052

Laitinen O, Kemppainen K, Ämmälä A, et al (2014) Use of Chemically Modified Nanocelluloses in Flotation of Hematite and Quartz. Ind Eng Chem Res 53:20092-20098. doi: 10.1021/ie503415t

Laitinen O, Niinimaki J (2014) Fractional Study of the Microfibrillated Cellulose. Tappi J 13:49-55.

Lou Y-R, Kanninen L, Kuisma T, et al (2014) The Use of Nanofibrillar Cellulose Hydrogel As a Flexible ThreeDimensional Model to Culture Human Pluripotent Stem Cells. Stem Cells Dev 23:380-392. doi: $10.1089 / \mathrm{scd} .2013 .0314$ 
Lyu B, Wang H-D, Ma J, et al (2016) Preparation and application of castor oil/nano-TiO2 composite fatliquoring agent via a Pickering emulsion method. J Clean Prod 126:711-716. doi: 10.1016/j.jclepro.2016.02.099

Malinen MM, Kanninen LK, Corlu A, et al (2014) Differentiation of liver progenitor cell line to functional organotypic cultures in 3D nanofibrillar cellulose and hyaluronan-gelatin hydrogels. Biomaterials 35:5110-5121. doi: 10.1016/j.biomaterials.2014.03.020

Ojala J, Sirviö JA, Liimatainen H (2016) Nanoparticle emulsifiers based on bifunctionalized cellulose nanocrystals as marine diesel oil-water emulsion stabilizers. Chem Eng J 288:312-320. doi: 10.1016/j.cej.2015.10.113

Pitkänen M, Kangas H, Laitinen O, et al (2014) Characteristics and safety of nano-sized cellulose fibrils. Cellulose. doi: 10.1007/s10570-014-0397-x

Prendergast DP, Gschwend PM (2014) Assessing the performance and cost of oil spill remediation technologies. J Clean Prod 78:233-242. doi: 10.1016/j.jclepro.2014.04.054

Ramachandran SD, Hodson PV, Khan CW, Lee K (2004) Oil dispersant increases PAH uptake by fish exposed to crude oil. Ecotoxicol Environ Saf 59:300-308. doi: 10.1016/j.ecoenv.2003.08.018

Ramachandran SD, Sweezey MJ, Hodson PV, et al (2006) Influence of salinity and fish species on PAH uptake from dispersed crude oil. Mar Pollut Bull 52:1182-1189. doi: 10.1016/j.marpolbul.2006.02.009

Rattaz A, Mishra SP, Chabot B, Daneault C (2011) Cellulose nanofibres by sonocatalysed-TEMPO-oxidation. Cellulose 18:585-593. doi: 10.1007/s10570-011-9529-8

Ruka DR, Sangwan P, Garvey CJ, et al (2015) Biodegradability of Poly-3-hydroxybutyrate/Bacterial Cellulose Composites under Aerobic Conditions, Measured via Evolution of Carbon Dioxide and Spectroscopic and Diffraction Methods. Environ Sci Technol 49:9979-9986. doi: 10.1021/es5044485

Segal L, Creely JJ, Martin AE, Conrad CM (1959) An empirical method for estimating the degree of crystallinity of native cellulose using the X-ray diffractometer. Text Res J 29:786-794.

Sirviö JA, Visanko M, Liimatainen H (2015) Deep eutectic solvent system based on choline chloride-urea as a pre-treatment for nanofibrillation of wood cellulose. Green Chem 17:3401-3406. doi: 10.1039/C5GC00398A

Sirviö JA, Visanko M, Liimatainen H (2016) Acidic deep eutectic solvents as hydrolytic media for cellulose nanocrystal production. Biomacromolecules. doi: 10.1021/acs.biomac.6b00910

Smith EL, Abbott AP, Ryder KS (2014) Deep Eutectic Solvents (DESs) and Their Applications. Chem Rev 114:11060-11082. doi: 10.1021/cr300162p

Van Hoecke K, De Schamphelaere KA, Van der Meeren P, et al (2008) Ecotoxicity of silica nanoparticles to the green alga Pseudokirchneriella subcapitata: importance of surface area. Environ Toxicol Chem 27:1948-1957.

Vartiainen J, Pöhler T, Sirola K, et al (2011) Health and environmental safety aspects of friction grinding and spray drying of microfibrillated cellulose. Cellulose 18:775-786. doi: 10.1007/s10570-011-9501-7 
Vikman M, Vartiainen J, Tsitko I, Korhonen P (2015) Biodegradability and Compostability of Nanofibrillar Cellulose-Based Products. J Polym Environ 23:206-215. doi: 10.1007/s10924-014-0694-3

Visanko M, Liimatainen H, Sirviö JA, et al (2014) Amphiphilic Cellulose Nanocrystals from Acid-Free Oxidative Treatment: Physicochemical Characteristics and Use as an Oil-Water Stabilizer. Biomacromolecules 15:2769-2775. doi: 10.1021/bm500628g

Wagle DV, Zhao H, Baker GA (2014) Deep Eutectic Solvents: Sustainable Media for Nanoscale and Functional Materials. Acc Chem Res 47:2299-2308. doi: 10.1021/ar5000488

Wu Y, Sun Q, Kong L, Fang $H$ (2014) Properties and microstructure of polymer emulsions modified fibers reinforced cementitious composites. J Wuhan Univ Technol-Mater Sci Ed 29:795-802. doi: 10.1007/s11595-014-0999-z

Xhanari K, Syverud K, Stenius P (2011) Emulsions Stabilized by Microfibrillated Cellulose: The Effect of Hydrophobization, Concentration and O/W Ratio. J Dispers Sci Technol 32:447-452. doi: 10.1080/01932691003658942

Yang JS, Jiang B, He W, Xia YM (2012) Hydrophobically modified alginate for emulsion of oil in water. Carbohydr Polym 87:1503-1506. doi: 10.1016/j.carbpol.2011.09.046

Yildirimer L, Thanh NTK, Loizidou M, Seifalian AM (2011) Toxicology and clinical potential of nanoparticles. Nano Today 6:585-607. doi: 10.1016/j.nantod.2011.10.001

Zhang Y, Chen D, Ennis AC, et al (2013) Chemical dispersant potentiates crude oil impacts on growth, reproduction, and gene expression in Caenorhabditis elegans. Arch Toxicol 87:371-382. doi: $10.1007 / \mathrm{s} 00204-012-0936-x$ 